\title{
Ilusões cognitivas e risco em decisões de investimento: uma análise das diferenças entre gênero
}

Desde a década de 1970, observam-se evidências de que as dinâmicas do processo decisório de investimento em ativos financeiros ocorrem fora do previsto pela teoria normativa de finanças. Daí a necessidade de elucidar a natureza dos fatores responsáveis por tais desvios. Essa análise requer a mudança de foco da precificação de ativos para o comportamento do agente financeiro e o contexto em que esse agente toma suas decisões. Uma vertente relativamente nova denominada "Finanças Comportamentais", tem se dedicado a analisar o efeito de heurísticas e ilusões cognitivas em decisões financeiras, tendo como premissa principal a sujeição dos indivíduos à característica limitada da racionalidade humana. Este estudo contribuiu para a construção desta agenda, tendo por objetivo descrever e analisar as possíveis diferenças entre gêneros com relação às dimensões de risco e aos vieses cognitivos apresentados por investidores potenciais. Para tanto, foram analisados os vieses cognitivos "ilusão de controle", "otimismo" e o efeito "melhor do que a média", e as dimensões "atitude", "percepção' e "perfil de risco". A coleta de dados deste estudo, de natureza descritiva quantitativa desenvolveu-se por meio de um survey, com base em um questionário composto por 46 questões. A amostra não probabilística selecionada compôs-se de um total de 464 discentes dos cursos de graduação em Administração e Ciências Contábeis e do curso de pós-graduação em Administração de Empresas de Instituição de Ensino Superior (IES) do estado de Minas Gerais. Os dados coletados foram submetidos a uma de análise estatística univariada e bivariada, contemplando especificamente a análise de correlação e a análise de diferença entre as médias dos grupos formados com base nas variáveis sociodemográficas. Os resultados apontam que no âmbito das especificidades de gênero as mulheres apresentaram maior nível de ilusão de controle que os homens em decisões de investimentos e de ativos financeiros. Com relação às dimensões de risco, o gênero masculino manifestou uma percepção mais clara de uma ação que o gênero feminino. O fator "atitude de risco" demonstrou que os homens arriscariam mais diante da possibilidade de um retorno mais alto no futuro. Quando as varáveis são comparadas em relação ao fator "idade", os mais jovens percebem melhor o risco das ações apresentadas. Quanto ao fator escolaridade, aqueles que estão cursando graduação mostraram-se mais propensos ao otimismo e à percepção de risco. No quesito "trabalho", os discentes que estão inativos apresentam influência do viés da ilusão de controle. Já os respondentes que trabalham percebem melhor o risco.

Palavras-chave: Finanças Comportamentais; llusões Cognitivas; Risco; Gênero.

\section{Cognitive illusions and risk in investment decisions: an analysis of gender differences}

\begin{abstract}
Since the 1970s it's seem that innumerous evidences that the dynamics of the decision-making process of investment in financial assets occur beyond what is foreseen by the normative theory of finance, evidencing the need to clarify the nature of the factors responsible for such deviations. Such analysis require a change on the focus on the pricing of the assets for the behavior of the finance agent and the context in which they take their decisions. So, a relatively new side called Behavioral Finance has been dedicated to the analysis of the heuristic effects and cognitive illusions in financial decisions, having as its main premise the subjection of the individuals to the limited feature of the human rationality. Opportunely, the present study contributed for this agenda, having as a goal the description and analysis of the possible differences between gender in relation to the risk dimensions and cognitive biases presented by the potential investors. For that, the cognitive biases control illusion, optimism and the effect "above average", the attitude dimensions, perception and risk profile were analyzed. The data collection in this qualitative-descriptive study was developed through a survey, based on a questionnaire of 46 questions. The probabilistic sample selected were made of 464 students of the Graduate course in Administration and Accounting and Post-Graduate course in Administration of Superior Degree (IES) of Minas Gerais. The data collected was analyzed by univariate and bivariate statistics, specially correlation analysis and difference analysis among mediums of the groups formed based on the sociodemographic variables. However, the results show, in the case of specified gender, that women showed a higher level of control illusion than the men on investment decisions and financial assets did. In relation to the risk dimensions, the men showed a clearer perspective of an action than the women did and the attitude factor of risk showed that men would risk further against the possibility of a higher outcome in the future. When the variables are compared, related to the age factor, the younger ones notice better the risk on the presented actions. On the education factor, those who are studying the graduate course are more likely to optimism and perception of risk. In the work factor, the students that are inactive in the work market, show influence of the control illusion bias. Thus, the ones who work, notice the risk better.
\end{abstract}

Keywords: Behavioral Finance; Cognitive Illusions; Risk; Gender.

\section{Topic: Finanças Empresariais}

Reviewed anonymously in the process of blind peer.

\section{Flávia Helena Faria}

Faculdade Novos Horizontes, Brasil

http://lattes.cnpq.br/1933675467965092

flaviahfaria@yahoo.com.br

Gustavo Rodrigues Cunha

Universita di Bologna, Itália

http://lattes.cnpq.br/6748300682848804

gustavo.rodrigues@unihorizontes.br
Received: 20/06/2016

Approved: 15/11/2016
Referencing this:

FARIA, F. H.; CUNHA, G. R.. Ilusões cognitivas e risco em decisões de investimento: uma análise das diferenças entre gênero. Revista Brasileira de Administração Científica, v.7, n.3, p.21-38, 2016. DOI: http://doi.org/10.6008/SPC2179-684X.2016.002.0002 


\section{INTRODUÇÃO}

A ciência financeira apresenta estágios importantes desde sua formação. Suas premissas fundamentam-se pelas perspectivas tradicional e moderna de finanças e assumem importância quando são realizados estudos que orientam o processo decisório de investimentos do mercado financeiro.

O paradigma tradicional, também conhecido como "teoria clássica", evoluiu com as atividades de compra e venda do mercado financeiro. Tem como base as ações que resultam em um retorno médio acima do mercado. Os participantes deste paradigma são os investidores ativos que pretendem obter rendimentos acima da média dos índices de mercado. ANOSFF (1965) e FAMA (1970).

O paradigma dominante, reconhecido como "teoria moderna de finanças", considera o investidor um agente econômico dotado de racionalidade absoluta, que a utiliza para auferir seus resultados em um mercado assumido como eficiente. Suas premissas encontram-se alicerçadas nos trabalhos importantes que promovem informações relevantes para o desenvolvimento da teoria dos jogos, de Neumann e Morgenster (1944), influência forte para a corrente de Markowitz (1955), que contempla os estudos sobre portfólio, risco e retorno e para teoria de mercado eficiente, proposta por Fama (1970).

Não obstante a força da teoria moderna de finanças, o surgimento de resultados empíricos contraditórios a ela e as críticas aos pressupostos da racionalidade absoluta de investidores trouxeram questionamentos sobre a validade das premissas adotadas pelos paradigmas existentes. Nesse contexto, desde a década de 1970 até a atualidade surgiram evidências de que as dinâmicas do processo decisório de investimento em ativos financeiros ocorrem fora do previsto pela teoria normativa de finanças (FAMÁ, 2002). Os sinais de desgastes são percebidos por meio de acontecimentos que fogem da normalidade e ficam conhecidos como "anomalias de mercados", por não perfazerem os modelos dos paradigmas clássico e moderno. São condizentes com a presença de vieses no comportamento humano, originados das limitações cognitivas capazes de comprometer a Hipótese de Mercado Eficiente.

Nas últimas décadas, desde aproximadamente 1970, observa-se o desenvolvimento substancial de um novo paradigma de finanças, com base na racionalidade limitada dos tomadores de decisões (SIMON, 1955). Esta nova vertente conceitual propõe descrever e analisar o comportamento real dos tomadores de decisão em investimentos.

A literatura avança nas discussões referentes às relações entre gênero e finanças. Os estudos apontam que quando estão diante de decisões financeiras as mulheres tendem a ser mais avessas ao risco que os homens e que as mesmas possuem maior sensibilidade quando estão presentes as incertezas dos retornos dos investimentos financeiros (GAVA; VIEIRA, 2006).

As variáveis de risco são importantes nos estudos de finanças e determinantes para a composição das pesquisas que focam as premissas do paradigma tradicional. Neste estudo, analisam-se a atitude, percepção e perfil de risco, variáveis significativas para a compreensão do processo decisório do investidor.

Esta investigação buscou descrever e explicar os aspectos manifestados no investidor, caracterizando as diferenças existentes neste agente no processo de decisão em investimentos, a fim de analisar a influência 
do fator gênero. Fez-se importante também analisar se o nível da variável risco ocorre em maior ou em menor proporção nas decisões de investimentos e se há a presença de ilusões cognitivas no comportamento do investidor.

\section{REFERENCIAL TEÓRICO}

\section{Teorias de Finanças}

O paradigma tradicional surgiu de atividades do dia a dia do mercado. Tem como base a formação de portfólios que resultem em um retorno médio acima do mercado. Os participantes adeptos deste paradigma são os investidores ativos, que realizam a gestão de suas atividades sempre em busca de vencer o mercado, isto é adquirir uma remuneração maior que a média do desempenho do mercado. A identificação dos preços dos ativos como subavaliados ou sobrevalorizados é conceituada como má precificação. Ela permite a avaliação de ações que levam o investidor a ganhar o mercado (BORSATO, 2009).

As finanças modernas surgiram como uma teoria alternativa, com funções, valor e probabilidades para caracterizar escolhas (GAVA et al., 2006). O seu surgimento na academia e nos departamentos de economia das universidades, ocorreu no início dos anos 1950. O interesse do fundador das finanças modernas por investimentos, Markowtiz, foi despertado quando este teórico teve o primeiro contato com os trabalhos desenvolvidos por Von Newman et al. (1944), que pressupõem uma alteração no comportamento do agente que garanta a imprevisibilidade dos seus atos. Esta teoria recebeu nome de "teoria dos jogos". Seu principal objetivo é evitar a informação de seus movimentos para outros que conseguissem lucros.

Os teóricos Van Newman et al. (1944) consolidam a racionalidade no comportamento e na tomada de decisões econômicas. Suas pressuposições causam impacto nos estudiosos do cenário econômico, principalmente no cenário de finanças. A publicação do artigo Portifolio Selection de Markowitz, no Jornal of Finance foi o marco da teoria moderna de portfólios (MTP).

Enquanto que para as finanças tradicionais o fator mais importante estava em um retorno acima da média de mercado, visto que o investidor, por meio do estudo do comportamento dos preços dos ativos, previa o comportamento do mercado, nas finanças modernas, também chamada de "teoria alternativa", os pesquisadores direcionavam os estudos para a racionalidade dos agentes, que, diferentemente do paradigma tradicional, presumiam a imprevisibilidade do mercado, pois o investidor é avesso ao risco, e desta forma, busca um retorno muito próximo à média de mercado (BORSATO, 2009).

Os primeiros desafios que questionam o comportamento do investidor foram as pesquisas realizadas e aplicadas de Tversky et al. (1974). Estes autores e psicólogos entenderam a visão da psicologia para à teoria econômica, utilizando-se do aprimoramento das técnicas de avaliação.

As finanças comportamentais surgem quando evidências empíricas impõem um desafio aos enfoques tradicionais. Thaler (1999) abriu o campo dos estudos que confrontam as falhas do modelo tradicional. Para 
ele, o entendimento do elemento humano enriquece consideravelmente a compreensão do cenário do mercado financeiro.

\section{Decisão em Finanças}

Tanto os gestores de empresas quanto os indivíduos que participam do mercado financeiro tomam decisões importantes que refletem diretamente nos resultados de seus ativos. Kimura (2003) coloca que os gestores de recursos financeiros devem ter habilidades técnicas e psicológicas adequadas para evitar armadilhas de tomada de decisão. Surge então a necessidade de uma análise extensa dos problemas que impactam o mercado financeiro e das anomalias de mercado. Processos que envolvem a incerteza necessitam alcançar clareza em busca de reduzir conflitos para decisões de investimento e financiamento do indivíduo.

Um fator evidente que influencia neste processo para os investidores individuais é que um bom planejamento é indispensável. Shefrin et al. (1985) orientam para a obtenção de um retorno esperado, em todo processo decisório as perdas, seja no curto prazo e os ganhos no longo prazo.

A área de finanças apresenta estudos e investigações em correntes predominantes, que são as finanças corporativas, que tratam das decisões internas, do desempenho e da avaliação do mercado financeiro. Para Assaf Neto (2003), o que cabe ao gestor financeiro no âmbito das finanças corporativas é a decisão que tem como consequência a ampliação da riqueza e dos valores, com base na estrutura de capital.

\section{Ilusões Cognitivas}

Para alguns autores, como Ackert et al. (2010) e Sternberg (2000), desvios são percebidos quando a atitude do investidor está envolvida com possíveis riscos. Estes são desvios inesperados de alguma decisão racional. Denominam-se "ilusões cognitivas".

Esclarecendo definições envolvidas no processo decisório do indivíduo e possíveis razões que explicam seu comportamento como agente econômico, necessário é esclarecer os aspectos que compõem a psicologia cognitiva. No anseio de investigar as possíveis influências destes vieses de cognição, é válido ressaltar que eles se relacionam e servem de base para a fundamentação desta pesquisa.

O viés da ilusão de controle, segundo Martinez (2003), trata da condução dos investidores quando adotam um comportamento que compreende tendências, já que a premissa deste viés está presente quando o agente investidor acredita ter acesso às informações com número mais elevado, adquirindo maior veracidade sobre suas escolhas.

O otimismo propõe a ocorrência de eventos favoráveis. Heaton (2002) encontrou em seus estudos experimentais resultados que mostram como as pessoas otimistas são excessivamente confiantes. Para Bandinelli (2010) o excesso de confiança e o otimismo, quando combinados, apresentam consequências de exagero ao superestimarem seus controles e habilidades diante dos eventos financeiros. Quando este fato acorre, acontece simultaneamente a subestimação dos riscos. Mesmo não desempenhando ações de surpresas quando falham em suas previsões, tornam-se vulneráveis. 
Para o efeito melhor do que a média, quando os indivíduos acreditam estarem acima da média, por exemplo, em relação ao senso de humor ou ao relacionamento com as outras pessoas e estas crenças estão erradas, estas habilidades podem permanecer diretamente enviesadas pelo otimismo. Para Milanez (2003), alguns aspectos, como inteligência e honestidade são destaques para esta variável, pois, comumente, assumem ser superior à média.

\section{Atitude, Percepção e Perfil de Risco}

Definido pela primeira vez, em 1952, como uma variável aleatória, o risco tornou-se base para uma ruptura inevitável nas ciências das finanças. Houve quebra. Surgiram definições que permitiram diferenciar a racionalidade no processo decisório, de mercados imprevisíveis e das finanças que concentram seus investimentos, propondo a previsão nos resultados. Moura (2005), coloca como grande colaborador desta teoria Daniel Bernoulli, em artigo considerado como o mais completo e de abordagens profundas e complexas, que incluíam enfoque estatístico e medições sobre o comportamento humano. "Risco é uma palavra que deriva do italiano riscare, que pode denotar 'ousar'" (MOURA, 2005).

No contexto da decisão de investimento, a atitude de risco está determinada pela "forma da tentativa de se medir o grau de incerteza na obtenção de retorno esperado em determinada aplicação financeira ou investimento realizado" (PUGA, 2009). Para Carneiro (2014), o investidor está propenso ao risco quando esta variável influencia seu comportamento para realizar avaliação seus ativos financeiros e de forma preponderante, escolhe a alternativa divergente a teoria da utilidade esperada, já que esta teoria presume a análise de todos os elementos que estão disponíveis.

Para Slovic (1999), os fatores que influenciam a percepção ou atitude arriscada do agente investidor podem ser distintos, citando-se a confiança, as expectativas e as aspirações, que o levarão a realizar a análise dos riscos. Ele considera inerente cada situação e que a cada contexto está relacionado a cada uma destas situações. O investidor enfrenta como situação central a determinação da avaliação dos riscos por esta ser uma etapa crítica que pode evidenciar erros na compreensão do próprio agente.

Os aspectos importantes que avaliam o perfil de risco são apontados para descrever a situação e a maneira como pesquisas estão sendo realizadas, com a intenção de avaliar a atitude e o perfil de risco dos investidores.

\section{Diferenças entre Gênero no Contexto de Decisões de Investimento}

As relações de gênero expressam um contexto teórico sob o ângulo de aportes de várias abordagens. Pesquisas são feitas sob a perspectiva interdisciplinar, quando se fundamentam disciplinas múltiplas, como sociologia, antropologia e história, perspectiva de construções subjetivas de fundamentos da psicanálise e perspectiva de fundamentos em reprodução das estruturas socioculturais subjetivos, que apontam resistência a novos modelos interpretativos de gênero. Entretanto, a compreensão dos diversos significados que este objeto possa incorporar não é o objetivo deste trabalho e não será tradado aqui a reestruturação 
dos modelos tradicionais de gêneros, e sim a relação que possa ter com a ciência financeira, principalmente com mercado acionário.

Strey et al. (2004) definem em suas concepções que o objeto teórico de análise das pesquisas empíricas é demasiadamente complexo, mas é fonte de interesse de vários doutrinadores nessa área de estudos. A abordagem de gênero contribui significativamente para desnaturalizar preconceitos, buscando responder questionamentos e problematizações de questões levantadas por aspectos epistemológicos e metodológicos (STREY et al., 2004).

Segundo Scalon (2005), existem esferas de ações distintas para ambos os gêneros. Mudanças estruturais de grande amplitude foram ocorrendo nas últimas décadas do século. XX. Fatores sociológicos, demográficos e econômicos são relevantes e de amplitude dimensional na vida social dos indivíduos. 0 aumento de escolaridade das mulheres promoveu o ingresso delas no mercado e, consequentemente, disponibilizou oportunidades que levam ao impacto do modelo tradicional. Uma nova posição é assumida nas práticas econômicas, colaborando por mudanças também significativas no cenário financeiro.

Gava e Vieira (2006) argumentam em seus estudos que as diferenças entre gênero são muito comentadas no mundo financeiro. "Quando se trata de decisões financeiras, as mulheres seriam mais avessas ao risco que os homens." Acrescentam, ainda, que a sensibilidade está mais presente para as mulheres quando relacionadas à ambiguidade e as incertezas referentes aos ativos financeiros investidos. Este fato leva à tendência de decisões de maior segurança, sendo contrário aos possíveis ganhos, e mostra uma diferença efetiva em relação aos homens.

Para Diniz (2013), estudos com a finalidade de avaliar o otimismo e o excesso de confiança fizeram relação do gênero ao nível de confiança. De acordo com este autor, as pesquisas de Klayman (2004) e Vesturlund (2007), revelaram que os homens tendem ser mais confiantes que as mulheres. Mas os estudos de Nekeby (2008) já relatam que algumas mulheres, quando selecionadas em ambientes sofridos por dominação masculina, tendem a ser pelo menos tão confiante quanto os homens.

\section{METODOLOGIA}

A presente pesquisa constitui um estudo empírico direcionado a análise dos fatos e processos e podem ser classificadas como "naturais" ou "sociais" (GIL, 2010). A abordagem desta investigação é de natureza quantitativa, por empregar a quantificação na produção dos seus resultados, por meio de técnicas estatísticas. Na abordagem quantitativa os testes estatísticos utilizados permitem auferir em termos numéricos a probabilidade de acertos em determinada conclusão (GIL, 2010).

A pesquisa assume características de finalidade descritiva, pois permite averiguar as formas comportamentais de uma amostra, por seus objetivos estarem bem definidos e estruturados, facilitando a busca para solução do problema formulado. Este estudo verificou a associação entre as variáveis de risco e as ilusões cognitivas. Definiu as ilusões cognitivas a serem pesquisadas: ilusão de controle, otimismo e o efeito melhor do que a média. Em seguida a pesquisa levantou características distintas entre gêneros. Para Gil (2010), entre as pesquisas descritivas salientam-se aquelas que têm por objetivo estudar as características 
entre grupos.

Quanto ao método de pesquisa, o estudo se realizou por meio de um survey. Malhotra (2004) afirma que as pesquisas descritivas podem utilizar vários métodos. Entre eles, destaca-se método survey, que tem como principal objetivo realizar o interrogatório dos respondentes, para levantar questões sobre comportamento, intenções e atitudes. Este método permite o tratamento dos dados das varáveis propostas nesta investigação.

Neste estudo, a população definida contemplou os discentes dos cursos de graduação em Administração e Ciências Contábeis e do curso de pós-graduação em Administração de Empresas. A composição da amostra escolhida compreendeu um total de 464 discentes de uma Instituição de Ensino Superior (IES) do estado de Minas Gerais. Esta amostra foi distribuída por 64 alunos de pós-graduação em Administração, 196 alunos de graduação do curso de Administração e 204 alunos de graduação do curso de Ciências Contábeis que estão matriculados e são frequentes no ano de 2015 nesta IES.

Com a pretensão de obter informações específicas do comportamento do indivíduo diante da decisão de investir, utilizou-se como instrumento de coleta de dados um questionário estruturado com questões de respostas diretas. "O questionário é um conjunto de perguntas (ou medidas) cujas respostas são registradas pelos respondentes, o que garante a validade das respostas" (HAIR JÚNIOR et al., 2006).

Os dados foram coletados, tabulados e submetidos as técnicas definidas, como a estatística descritiva e a análise de variância, por meio do procedimento estatístico bivariado. A análise de variância tem como objetivo principal a redução ou a condensação de dados, para identificar as dimensões que expliquem as correlações de um conjunto de variáveis (MALHOTRA, 2004).

As técnicas definidas como estratégias foram: a análise estatística univariada, via tabela de frequência para variáveis qualitativas e medidas descritivas para variáveis do tipo Likert, e a análise bivariada, descrita pelo teste t, pela análise de variância e pela correlação de Pearson. Os conceitos atribuídos aos resultados foram medidos seguindo as dimensões de seus significados e se justificam com a utilidade para as diretrizes propostos (BABBIE, 2005).

A análise dos dados iniciou-se com o exame das características demográfico-ocupacionais, seguindo para as questões relacionadas às variáveis relativas ao risco e às ilusões cognitivas dos discentes pesquisados. Foram utilizados testes paramétricos para dados ordinais de escala Likert, pois o teorema central do limite demonstra que para tamanhos de amostra superiores a 5 ou 10 por grupo as médias apresentam, aproximadamente, distribuição normal, independentemente da distribuição de dados ordinais.

O exame de fidedignidade foi abordado por meio da avaliação de sua consistência interna. Como orientam Churchill (1979), Spector (1992) e Urdan (1995), neste trabalho optou-se pelo exame de consistência interna das escalas existentes no instrumento de coleta de dados referente as seções B, C, D, I e L, por meio do cálculo do coeficiente de alfa de Cronbach das sub-escalas, que determina o quanto os itens da escala estão inter-relacionados. Apesar de ser semelhante, este indicador não deve ser confundido com índices de correlação. 
Para realizar uma análise consistente capaz de determinar características que apresentem resultados eficientes das relações entre as variáveis e as tendências presentes no comportamento do investidor no contexto de decisões financeiras, os dados da pesquisa foram tratados no programa estatístico Predictive Analytics Software (PASW 18). Em todos os testes estatísticos utilizados foi considerado um nível de significância de 5\%. Dessa forma, são consideradas associações estatisticamente significativas aquelas cujo valor $\mathrm{p}$ foi inferior a 0,05 .

\section{RESULTADOS E DISCUSSÃO}

Para responder aos objetivos da pesquisa e identificar os fatores influentes no comportamento dos respondentes selecionados procedeu-se nesta seção à interpretação dos dados considerados válidos sobre os discentes que perfazem a amostra pesquisada.

Esta seção compõe-se de três etapas. Na primeira, os resultados são descritos a partir da distribuição de frequências e das medidas descritivas. Na segunda, realizou-se o exame de consistência interna das escalas existentes, por meio do cálculo do coeficiente de Alfa de Cronbach das sub-escalas. Na terceira, os dados são apresentados e discutidos mediante a utilização de procedimento estatístico bivariado, cuja finalidade é observar a associação das variáveis de acordo com seus constructos. Dentro da normalidade dos procedimentos, utilizou-se a associação das ilusões cognitivas e das variáveis do risco com os dados demográficos funcionais.

\section{Análise Descritiva: Dados Sociodemográficos}

Compõe esta pesquisa uma amostra de 464 discentes de uma Instituição de Ensino Superior do estado de Minas Gerais. Em termos percentuais, compreende 53,4\% de alunos com idade de até 25 anos, $18,9 \%$ de alunos com idade entre 25 a 30 anos e $11,3 \%$ de alunos com idade de 31 a 35 anos. Os demais resultados podem ser percebidos na Tabela 1.

Tabela 1: Distribuição da amostra segundo a faixa etária.

\begin{tabular}{|l|r|r|}
\hline \multicolumn{1}{|c|}{ Faixa etária } & $\mathbf{N}$ \\
\hline até 25 anos & \% & 248 \\
\hline de 25 a 30 anos & 83,4 \\
\hline de 31 a 35 anos & 18,9 \\
\hline de 36 a 40 anos & 52 & 31,3 \\
\hline de 41 a 45 anos & 6,6 \\
\hline de 46 anos a 50 anos & 3,9 \\
\hline acima de 50 anos & 3,5 \\
\hline Total & 18 & 16 \\
\hline
\end{tabular}

Os resultados permitem perceber que em relação ao gênero a descrição do total de respondentes está distribuída entre 315 respondentes do sexo feminino (68,0\%) e 149 do sexo masculino (32,0\%). A Tabela 2 ilustra a distribuição segundo o sexo. O gênero feminino tem representatividade importante e predominante entre os entrevistados. 
Tabela 2: Distribuição da amostra segundo o gênero.

\begin{tabular}{|l|r|r|}
\hline \multicolumn{1}{|c|}{ Gênero } & N & \% \\
\hline Masculino & 149 & 32,0 \\
\hline Feminino & 315 & 68,0 \\
\hline Total & 464 & 100,0 \\
\hline
\end{tabular}

No que se refere ao grau de escolaridade dos respondentes, $76,9 \%$ possuem graduação incompleta, sendo que $11,3 \%$ representam os alunos que possuem pós-graduação strictu sensu completa.

Tabela 3: Distribuição da amostra segundo o grau de escolaridade.

\begin{tabular}{|l|r|r|}
\hline \multicolumn{1}{|c|}{ Grau de escolaridade } & N & \% \\
\hline Superior incompleto & 357 & 76,9 \\
\hline Superior completo & 25 & 5,3 \\
\hline Especialização completa & 6 &, 8 \\
\hline Especialização incompleta & 3 &, 6 \\
\hline Pós-graduação Latu Sensu Completa & 11 & 8 \\
\hline Pós-graduação Latu Sensu Incompleta & 2,3 \\
\hline Pós-graduação Strictu Senso Completa & 2 & 1,7 \\
\hline Pós-graduação Strictu Senso Completa & 52 &, 4 \\
\hline Total & 464 & 11,3 \\
\hline
\end{tabular}

Compõe esta pesquisa, em termos de tamanho, uma amostra de 64 alunos que estão cursando pósgraduação em Administração, 196 em Administração e 204 em Ciências Contábeis (Tabela 4).

Tabela 4: Distribuição da amostra segundo o grupo.

\begin{tabular}{|l|r|r|}
\hline \multicolumn{1}{|c|}{ Grupo } & N & \multicolumn{1}{|c|}{$\%$} \\
\hline Pós-Graduação & 64 & 13,8 \\
\hline Graduação em Administração & 196 & 42,2 \\
\hline Graduação em Contabilidade & 204 & 44,0 \\
\hline Total & 464 & 100,0 \\
\hline
\end{tabular}

Tabela 5: Distribuição da amostra segundo o conhecimento em finanças.

\begin{tabular}{|l|r|r|}
\hline Qual o seu conhecimento da área de finanças? & $\mathbf{n}$ & $\mathbf{\%}$ \\
\hline Curso de qualificação & 116 & 34,8 \\
\hline Curso de aperfeiçoamento & 24 & 7,2 \\
\hline Curso técnico & 64 & 19,2 \\
\hline Curso de graduação & 110 & 33,0 \\
\hline Curso de pós-graduação Latu Senso & 16 & 4,8 \\
\hline Curso de pós-graduação Strictu Senso & 3 &, 9 \\
\hline Total & 333 & 100,0 \\
\hline
\end{tabular}

Apurou-se que a grande maioria dos respondentes não possui experiência vivenciada por meio de pesquisas ou vivência teórico-acadêmica na área de finanças ou de investimentos, sendo que (72,0\%) não apresentam vivência teórico-acadêmica com finanças ou investimentos (Tabela 6).

Tabela 6: Distribuição da amostra segundo a vivência teórico-acadêmica com finanças ou investimentos.

\begin{tabular}{|l|c|c|}
\hline $\begin{array}{l}\text { Possui vivência teórico-acadêmica anterior com Finanças ou Investimentos, quer seja através de pesquisas ou cursando } \\
\text { disciplinas como Administração Financeira, Análise de Investimentos, Mercado de Capitais ou Tópicos em Finanças? }\end{array}$ & $\mathbf{N}$ & $\%$ \\
\hline Sim & 130 & 28,0 \\
\hline Não & 334 & 72,0 \\
\hline Total & 464 & 100,0 \\
\hline
\end{tabular}

\section{Validação da Escala}

O exame de fidedignidade foi feito por meio do coeficiente de consistência interna conhecido como "Alfa de Cronbach", de modo a verificar se as questões referentes a cada tipo de fator estavam realmente representando seus respectivos grupos. Foi calculado para cada uma das sub-escalas do questionário. 
De maneira geral, as questões de cada tipo de viés das variáveis relativas ao risco e as ilusões cognitivas dos discentes pesquisados tiveram praticamente confirmadas às suas dimensionalidades. Ou seja, apresentaram uma consistência interna satisfatória, pois o valor de alfa foi superior que 0,5 (Tabela 7 a 12). Merece destaque o efeito melhor do que a média, que apresentou consistência satisfatória, alfa = 0,852.

Tabela 7: Avaliação da consistência interna referente a llusão de Controle na amostra total.

\begin{tabular}{|l|l|}
\hline \multicolumn{1}{|c|}{ Ilusão de controle } & Alfa \\
\hline $\begin{array}{l}\text { B1 Se eu investisse na Bolsa de Valores acredito que dificilmente as ações das empresas que eu escolhesse apresentariam resultados } \\
\text { negativos no futuro. }\end{array}$ & 0,553 \\
\hline B3 A análise adequada leva a previsões quase sempre corretas sobre o valor futuro das ações. \\
\hline B5 É possível ter rendimentos acima da média do mercado (IBOVESPA) com frequência. \\
\hline $\begin{array}{l}\text { B6 Não é necessário manter muitas ações no portfólio (conjunto de ações, carteira de investimentos), já que eu sou bastante capaz de } \\
\text { encontrar as ações boas para investir. }\end{array}$ \\
\hline B7 Se me concentrar bastante, eu sou capaz de influenciar se eu ganho ou não quando invisto no mercado de ações. \\
\hline B8 Para ganhar no mercado de ações, você tem de pensar positivamente. \\
\hline
\end{tabular}
Nota: As questões B1, B3, B5, B6, B7 e B8 foram invertidas para a análise do teste.

Tabela 8: Avaliação da consistência interna referente a Atitude de Risco na amostra total.

\begin{tabular}{|l|l|}
\hline \multicolumn{1}{|c|}{ Atitude de risco } & Alfa \\
\hline C1 Investir 10\% da sua remuneração em caderneta de poupança & 0,557 \\
\hline C2 Investir 10\% da sua remuneração em títulos de curto prazo do governo (SELIC) \\
\hline $\begin{array}{l}\text { C3 Investir 10\% da sua remuneração em um fundo de ações de crescimento moderado, ou seja, um fundo que ofereça a valorização do } \\
\text { capital investido no longo prazo sem perda da estabilidade do valor investido. }\end{array}$ & \\
\hline
\end{tabular}

Tabela 9: Avaliação da consistência interna referente a Melhor que a Média na amostra total.

\begin{tabular}{|l|c|}
\hline \multicolumn{1}{|c|}{ Melhor que a média } & Alfa \\
\hline D1 Capacidade e velocidade em interpretar novas informaçes. & \\
\hline D2 Equilíbrio mental em cenários de crise no mercado financeiro. & 0,852 \\
\hline D3 Habilidade em encontrar informações relevantes. & \\
\hline D4 Capacidade de identificar oportunidades de investimento. & \\
\hline D5 Percepção do momento certo de agir, ou seja, comprar ou vender ativos financeiros. & \\
\hline
\end{tabular}

Tabela 10: Avaliação da consistência interna referente ao otimismo na amostra total.

\begin{tabular}{|l|c|}
\hline \multicolumn{1}{|c|}{ Otimismo } & Alfa \\
\hline 11 Eu raramente conto com coisas boas acontecendo comigo & \multirow{2}{*}{0,504} \\
\hline 13 Eu quase nunca espero que as coisas aconteçam do meu jeito & \\
\hline 17 Se alguma coisa puder dar errado para mim, isto acontecerá & \\
\hline
\end{tabular}

Nota: As questões I1, 13 e 17 foram invertidas para a análise do teste.

Tabela 11: Avaliação da consistência interna referente ao Perfil de Risco na amostra total.

\begin{tabular}{|l|l|}
\hline \multicolumn{1}{|c|}{ Perfil de risco } \\
\hline é esperado de investimentos estáveis
\end{tabular}

\section{Análise das Variáveis de Risco e das Ilusões Cognitivas}

Foram analisados os dados decorrentes do comportamento dos entrevistados nas decisões de investimento. Estas análises buscaram a compreensão dos respondentes para o viés da ilusão de controle e a determinação das características significativas das variáveis de risco. As respostas ao instrumento de coleta de dados para estas perguntas foram do tipo LIKERT de cinco pontos. Para sintetizar as informações de cada pergunta, utilizaram-se a média e a mediana como medida de tendência central. Para a medida de dispersão, utilizaram-se o desvio-padrão e o intervalo interquartil $\left(\mathrm{P}_{25}\right.$ e $\left.\mathrm{P}_{75}\right)$. A Tabela 12 mostra os resultados do sentimento dos alunos em relação à decisão de investimento. 
Tabela 12: Avaliação dos escores referentes à ilusão de controle na amostra total.

\begin{tabular}{|c|c|c|c|c|c|c|c|}
\hline \multirow{2}{*}{ llusão de controle } & \multicolumn{5}{|c|}{ Medidas Descritivas } & \multirow{2}{*}{ P-valor } & \multirow{2}{*}{ Conclusão } \\
\hline & Média & D.P & 1Q & Mediana & $3 Q$ & & \\
\hline $\begin{array}{l}\text { B1 Se eu investisse na Bolsa de Valores acredito que dificilmente as ações } \\
\text { das empresas que eu escolhesse apresentariam resultados negativos no } \\
\text { futuro. }\end{array}$ & 2,93 & 1,00 & 2,00 & 3,00 & 4,00 & \multirow{6}{*}{$p<0,001^{* *}$} & \multirow{6}{*}{$\begin{aligned} \mathrm{B} 3 & >\mathrm{B} 8>\mathrm{B} 5= \\
\mathrm{B} 7 & >\mathrm{B} 1>\mathrm{B} 6\end{aligned}$} \\
\hline $\begin{array}{l}\text { B3 A análise adequada leva a previsões quase sempre corretas sobre o } \\
\text { valor futuro das ações. }\end{array}$ & 3,65 & 1,26 & 3,00 & 4,00 & 4,00 & & \\
\hline $\begin{array}{l}\text { B5 É possível ter rendimentos acima da média do mercado (IBOVESPA) } \\
\text { com frequência. }\end{array}$ & 3,02 & 0,80 & 3,00 & 3,00 & 4,00 & & \\
\hline $\begin{array}{l}\text { B6 Não é necessário manter muitas ações no portfólio (conjunto de ações, } \\
\text { carteira de investimentos) já que eu sou bastante capaz de encontrar as } \\
\text { ações boas para investir. }\end{array}$ & 2,75 & 0,86 & 2,00 & 3,00 & 3,00 & & \\
\hline $\begin{array}{l}\text { B7 Se me concentrar bastante eu sou capaz de influenciar se eu ganho ou } \\
\text { não quando invisto no mercado de ações. }\end{array}$ & 3,10 & 1,00 & 2,00 & 3,00 & 4,00 & & \\
\hline B8 Para ganhar no mercado de ações você tem de pensar positivam & 3,14 & 1,52 & 2,00 & 3,00 & 4,00 & & \\
\hline
\end{tabular}

Notas: (a) As probabilidades de significância (p-valor) referem-se ao teste de Friedman. (b) As questões B1, B3, B5, B6, B7 e B8 foram invertidas para a análise do teste. (c) Os resultados significativos foram identificados com asteriscos, de acordo com o nível de significância, a saber: $p$-valor $<0.01 * *$ (nível de confiança de $99,0 \%$ ) e p-valor $<0.05 *$ (nível de confiança de 95,0\%). (d) O resultado da conclusão foi obtido por meio do teste Wilcoxon realizado múltiplas vezes.

O comportamento dos entrevistados no que diz respeito à atitude de risco para investir revelou um escore mediano de 2,00 em boa parte das questões da TAB 13, evidenciando uma situação de concordância de atitude de risco por parte dos informantes. O teste estatístico de Friedman sinalizou que o indicador de investimento SELIC apresenta maior discordância entre os entrevistados.

Tabela 13: Avaliação dos escores referentes a atitude de risco na amostra total.

\begin{tabular}{|c|c|c|c|c|c|c|c|}
\hline \multirow[b]{2}{*}{ Atitude de risco } & \multicolumn{5}{|c|}{ Medidas descritivas } & \multirow{2}{*}{ P-valor } & \multirow{2}{*}{ Conclusão } \\
\hline & Média & D.P & $1 Q$ & Mediana & $3 Q$ & & \\
\hline C1 Investir $10 \%$ da sua remuneração em caderneta de poupança & 2,06 & 0,96 & 1,00 & 2,00 & 2,00 & \multirow{3}{*}{$p<0,001 * *$} & \multirow{3}{*}{$\begin{array}{c}\mathrm{C} 2>\mathrm{C} 3> \\
\quad \mathrm{C} 1\end{array}$} \\
\hline $\begin{array}{l}\text { C2 Investir 10\% da sua remuneração em títulos de curto prazo do governo } \\
\text { (SELIC) }\end{array}$ & 3,07 & 0,93 & 3,00 & 3,00 & 4,00 & & \\
\hline $\begin{array}{l}\text { C3 Investir } 10 \% \text { da sua remuneração em um fundo de ações de crescimento } \\
\text { moderado, ou seja, um fundo que ofereça a valorização do capital investido no } \\
\text { longo prazo sem perda da estabilidade do valor investido. }\end{array}$ & 2,45 & 0,93 & 2,00 & 2,00 & 3,00 & & \\
\hline
\end{tabular}

Notas: (a) As probabilidades de significância ( $p$-valor) referem-se ao teste de Friedman. (b) Os resultados significativos foram identificados com asteriscos, de acordo com o nível de significância, a saber: p-valor $<0.01 * *$ (nível de confiança de $99,0 \%$ ) e p-valor $<0.05 *$ (nível de confiança de $95,0 \%)$. (c) O resultado da conclusão foi obtido por meio do teste Wilcoxon realizado múltiplas vezes.

A seção $D$ do instrumento pontua o efeito melhor do que a média. Essa ilusão cognitiva decorre do comportamento do indivíduo em comparação com outros indivíduos.

Tabela 14: Avaliação dos escores referente a melhor do que a média na amostra total.

\begin{tabular}{|c|c|c|c|c|c|c|c|}
\hline \multirow{2}{*}{ Melhor do que a média } & \multicolumn{5}{|c|}{ Medidas Descritivas } & \multirow{2}{*}{ P-valor } & \multirow{2}{*}{ Conclusão } \\
\hline & Média & D.P & 1Q & Mediana & $3 Q$ & & \\
\hline D1 Capacidade e velocidade em interpretar novas informações. & 6,00 & 2,31 & 4,00 & 6,00 & 8,00 & \multirow{5}{*}{$\mathrm{p}<0,001 * *$} & \multirow{5}{*}{$\begin{array}{c}\mathrm{D} 1=\mathrm{D} 3=\mathrm{D} 4>\mathrm{D} 2= \\
\mathrm{D} 5\end{array}$} \\
\hline D2 Equilíbrio mental em cenários de crise no mercado financeiro. & 5,81 & 2,31 & 4,00 & 6,00 & 8,00 & & \\
\hline D3 Habilidade em encontrar informações relevantes. & 6,09 & 2,37 & 5,00 & 6,00 & 8,00 & & \\
\hline D4 Capacidade de identificar oportunidades de investimento. & 5,97 & 3,66 & 4,00 & 6,00 & 8,00 & & \\
\hline $\begin{array}{l}\text { D5 Percepção do momento certo de agir, ou seja, comprar ou vender } \\
\text { ativos financeiros. }\end{array}$ & 5,79 & 2,37 & 4,00 & 6,00 & 8,00 & & \\
\hline
\end{tabular}

Notas: (a) As probabilidades de significância (p-valor) referem-se ao teste de Friedman. (b) Os resultados significativos foram identificados com asteriscos, de acordo com o nível de significância, a saber: $p$-valor $<0.01 * *$ (nível de confiança de 99,0\%) e p-valor $<0.05 *$ (nível de confiança de $95,0 \%)$. (c) O resultado da conclusão foi obtido por meio do teste Wilcoxon realizado múltiplas vezes.

As seções $E, F, G, G 1$ e $H$ representam os aspectos pertinentes à percepção de risco pelos respondentes. Indicam o preço das ações nos últimos seis meses. Foram realizadas as seguintes alterações nas respostas dos entrevistados, de modo que a análise dos dados apresente melhor esclarecimento: Quanto às variáveis pertencentes a cada gráfico do questionário, a operação matemática e seu respectivo significado, destacam-se a seguir: (1) Preço da ação A nos últimos seis meses (E) - resultante do cálculo da diferença da 
questão E do questionário pelo valor absoluto 2 para cada respondente individualmente; (2) Preço da ação $B$ nos últimos seis meses $(F)$ - resultante do cálculo da diferença da questão $F$ do questionário pelo valor absoluto 3 para cada respondente individualmente; (3) Preço da ação C nos últimos seis meses (G) resultante do cálculo da diferença da questão $\mathrm{G}$ do questionário pelo valor absoluto 5 para cada respondente individualmente; (4) Preço da ação D nos últimos seis meses (G1) - resultante do cálculo da diferença da questão G1 do questionário pelo valor absoluto 2 para cada respondente individualmente; (5) Preço da ação E nos últimos seis meses $(\mathrm{H})$ - resultante do cálculo da diferença da questão $\mathrm{H}$ do questionário pelo valor absoluto 4 para cada respondente individualmente. A Tabela 20 mostra os resultados da percepção dos alunos em relação ao risco de investimento nas ações.

Tabela 15: Avaliação dos escores referente a ações na amostra total.

\begin{tabular}{|l|r|r|r|r|r|}
\hline \multicolumn{1}{|c|}{ Ações } & \multicolumn{4}{c|}{ Medidas descritivas } \\
\cline { 2 - 6 } & \multicolumn{1}{|c|}{ Média } & \multicolumn{1}{c|}{ D.P } & \multicolumn{1}{c|}{$\mathbf{1 Q}$} & \multicolumn{1}{c|}{ Mediana } & \multicolumn{1}{c|}{$\mathbf{3 Q}$} \\
\hline E- Preço da Ação A nos últimos 6 meses do questionário & 0,69 & 0,91 & 0,00 & $-1,00$ & 1,00 \\
\hline F- Preço da Ação B nos últimos 6 meses & $-0,25$ & 0,93 & $-1,00$ & 0,00 & 0,00 \\
\hline G- Preço da Ação C nos últimos 6 meses & $-0,94$ & 2,09 & $-1,00$ & $-1,00$ & 0,00 \\
\hline G1- Preço da Ação D nos últimos 6 meses & 0,26 & 0,99 & 0,00 & 0,00 & 1,00 \\
\hline H- Preço da Ação E nos últimos 6 meses & $-0,93$ & 1,37 & $-1,00$ & $-1,00$ & 0,00 \\
\hline
\end{tabular}

Conforme se observa na Tabela 16, os alunos apresentaram uma percepção esperada do risco na ação $G 1$, visto que o escore mediano foi de zero. Já para as ações $E, G$ e H os alunos apresentaram uma percepção reduzida do risco, pois o escore mediano foi de $-1,00$. Nesta análise, nenhum resultado apresentou percepção acentuada pelos respondentes.

Tabela 16: Avaliação dos escores referentes ao otimismo na amostra total.

\begin{tabular}{|c|c|c|c|c|c|c|c|}
\hline \multirow{2}{*}{ Otimismo } & \multicolumn{5}{|c|}{ Medidas Descritivas } & \multirow{2}{*}{ P-valor } & \multirow{2}{*}{ Conclusão } \\
\hline & Média & D.P & $1 Q$ & Mediana & $3 Q$ & & \\
\hline I1 Eu raramente conto com coisas boas acontecendo comigo & 3,64 & 1,14 & 3,00 & 4,00 & 4,00 & \multirow{3}{*}{$\mathrm{p}<0,001 * *$} & \multirow{3}{*}{$11>13>17$} \\
\hline I3 Eu quase nunca espero que as coisas aconteçam do meu jeito & 3,31 & 1,14 & 2,00 & 4,00 & 4,00 & & \\
\hline I7 Se alguma coisa puder dar errado para mim, isto acontecerá & 3,19 & 1,14 & 2,00 & 3,00 & 4,00 & & \\
\hline
\end{tabular}

Notas: (a) As probabilidades de significância (p-valor) referem-se ao teste de Friedman. (b) As questões I1, 13 e I7 foram invertidas para a análise do teste. (c) Os resultados significativos foram identificados com asteriscos, de acordo com o nível de significância, a saber: $p$-valor < $0.01 * *$ (nível de confiança de $99,0 \%$ ) e p-valor < 0.05 * (nível de confiança de 95,0\%). (d) O resultado da conclusão foi obtido por meio do teste Wilcoxon realizado múltiplas vezes.

Em uma análise comparativa dos escores referentes ao perfil de risco entre os alunos pesquisados, verificou-se a existência de diferenças significativas quanto a esta ilusão cognitiva, pois o teste apresentou um valor-p de 0,001**.

O indicador Eu estou financeiramente apto a aceitar um baixo nível de liquidez em minha carteira de investimentos, foi o mais discordante entre os alunos $(3,22)$ (Tabela 17).

A interpretação deste resultado permite concluir que os entrevistados concordam quanto a tolerar ou a arriscar uma perda imediata diante da possibilidade de ganho futuro. 
Tabela 17: Avaliação dos escores referentes ao perfil de risco na amostra total.

\begin{tabular}{|c|c|c|c|c|c|c|c|}
\hline \multirow{2}{*}{ Perfil de Risco } & \multicolumn{5}{|c|}{ Medidas descritivas } & \multirow{2}{*}{ P-valor } & \multirow{2}{*}{ Conclusão } \\
\hline & Média & D.P & 10 & Mediana & $3 Q$ & & \\
\hline $\begin{array}{l}\text { L4 Eu toleraria variações bruscas no retorno dos meus investimentos para obter } \\
\text { um retorno potencialmente mais alto do que normalmente é esperado de } \\
\text { investimentos estáveis }\end{array}$ & 2,90 & 0,95 & 2,00 & 3,00 & 4,00 & \multirow{3}{*}{$p<0,001 * *$} & \multirow{3}{*}{$\begin{array}{l}\mathrm{L} 4=\mathrm{L} 5> \\
\quad \mathrm{L} 6\end{array}$} \\
\hline $\begin{array}{l}\text { L5 Eu arriscaria uma perda no retorno de curto prazo por uma possibilidade de } \\
\text { uma taxa de retorno mais alto no futuro. }\end{array}$ & 2,89 & 1,02 & 2,00 & 3,00 & 4,00 & & \\
\hline $\begin{array}{l}\text { L6 Eu estou financeiramente apto a aceitar um baixo nível de liquidez em minha } \\
\text { carteira de investimentos. }\end{array}$ & 2,47 & 0,94 & 2,00 & 3,00 & 3,00 & & \\
\hline
\end{tabular}

Notas: (a) As probabilidades de significância (p-valor) referem-se ao teste de Friedman. (b) Os resultados significativos foram identificados com asteriscos, de acordo com o nível de significância, a saber: $p$-valor $<0.01^{* *}$ (nível de confiança de $99,0 \%$ ) e $p$-valor $<0.05 *$ (nível de confiança de $95,0 \%)$. (c) O resultado da conclusão foi obtido por meio do teste Wilcoxon realizado múltiplas vezes.

\section{Análise de Associação}

Realizou-se a análise de associação, que comprova as relações das variáveis com os objetivos do estudo. Este procedimento tem a função de analisar a presença e as diferenças possíveis destes vieses quando relacionadas e comparadas com o perfil sócio demográfico dos respondentes, sobretudo nas especificidades de gênero.

Tabela 18: Avaliação dos escores médios referentes aos fatores das variáveis ao risco e as ilusões cognitivas dos discentes pesquisados por gênero.

\begin{tabular}{|c|c|c|c|c|c|}
\hline Questões sobre medidas psicométricas & Gênero & Média & D.P & Estatística T & P-valor \\
\hline \multirow{2}{*}{ Soma dos escores do item B do questionário (Ilusão de Controle) } & Masculino & 18,35 & 3,26 & $-0,766$ & 0,444 \\
\hline & Feminino & 18,64 & 3,86 & & \\
\hline \multirow{2}{*}{ Soma dos escores do item C do questionário (Atitude de Risco) } & Masculino & 7,63 & 2,31 & 0,324 & 0,746 \\
\hline & Feminino & 7,56 & 1,93 & & \\
\hline \multirow{2}{*}{ Soma dos escores do item D do questionário (Melhor que a Média) } & Masculino & 30,48 & 10,99 & 1,094 & 0,274 \\
\hline & Feminino & 29,33 & 10,28 & & \\
\hline \multirow{2}{*}{ E- Preço da Ação A nos últimos 6 meses do questionário } & Masculino & 0,65 & 0,95 & $-0,553$ & 0,580 \\
\hline & Feminino & 0,70 & 0,89 & & \\
\hline \multirow{2}{*}{ F- Preço da Ação B nos últimos 6 meses } & Masculino & $-0,24$ & 0,86 & 0,114 & 0,909 \\
\hline & Feminino & $-0,26$ & 0,97 & & \\
\hline \multirow{2}{*}{ G- Preço da Ação C nos últimos 6 meses } & Masculino & $-0,77$ & 0,97 & 1,153 & 0,250 \\
\hline & Feminino & $-1,01$ & 2,44 & & \\
\hline \multirow{2}{*}{ G1- Preço da Ação D nos últimos 6 meses } & Masculino & 0,11 & 1,01 & $-2,231$ & 0,026 \\
\hline & Feminino & 0,33 & 0,97 & & \\
\hline \multirow{2}{*}{ H-Preço da Ação E nos últimos 6 meses } & Masculino & $-1,01$ & 0,98 & $-0,912$ & 0,362 \\
\hline & Feminino & $-0,89$ & 1,53 & & \\
\hline \multirow{2}{*}{ Soma dos escores do item I do questionário (Otimismo) } & Masculino & 9,93 & 2,47 & $-1,207$ & 0,228 \\
\hline & Feminino & 10,22 & 2,39 & & \\
\hline \multirow{2}{*}{ Soma dos escores do item L do questionário (Perfil de Risco) } & Masculino & 8,53 & 2,30 & 1,824 & 0,069 \\
\hline & Feminino & 8,14 & 2,09 & & \\
\hline
\end{tabular}

Notas: (a) As probabilidades de significância (p-valor) referem-se ao teste t-Student para amostras independentes. (b) Os valores de p-valor em negrito indicam diferenças significativas. (c) Os resultados significativos foram identificados com asteriscos, de acordo com o nível de significância, a saber: p-valor $<0.01^{* *}$ (nível de confiança de 99\%) e p-valor $<0.05 *$ (nível de confiança de 95\%).

A Tabela 19 mostra o resultado dos níveis médio dos fatores variáveis de risco e ilusões cognitivas dos discentes pesquisados entre as três categorias de faixa etária: até 25 anos; de 25 a 30; e acima de 31 . Os alunos com até 25 anos de idade apresentaram uma percepção esperada do risco na ação $A$ mais precisa do que os demais grupos, visto que o escore médio $(0,56)$ foi mais próximo de zero do que os demais grupos.

No que se refere à associação entre os grupos de escolaridade e os fatores de variáveis de risco e as ilusões cognitivas dos discentes pesquisados, conforme demonstra a Tabela 21, os alunos de graduação apresentaram maior concordância para perfil de risco e otimismo quando comparados aos alunos de pósgraduação. 
Tabela 19: Avaliação dos escores médios referentes aos fatores de variáveis de risco e as ilusões cognitivas dos discentes pesquisados por faixa etária.

\begin{tabular}{|c|c|c|c|c|c|}
\hline Questões sobre medidas psicométricas & Faixa Etária & Média & D.P & Estatística F & P-valor \\
\hline \multirow{3}{*}{ Soma dos escores do item B do questionário (Ilusão de controle) } & Até 25 anos & 19,32 & 3,14 & 7,705 & $0,001 * *$ \\
\hline & De 25 a 30 anos & 17,41 & 2,99 & & \\
\hline & Acima de 31 anos & 17,76 & 4,63 & & \\
\hline \multirow{3}{*}{ Soma dos escores do item C do questionário (atitude de risco) } & Até 25 anos & 7,55 & 1,87 & 0,738 & 0,816 \\
\hline & De 25 a 30 anos & 7,51 & 2,22 & & \\
\hline & Acima de 31 anos & 7,67 & 2,26 & & \\
\hline \multirow{3}{*}{ Soma dos escores do item $\mathrm{D}$ do questionário (melhor do que a média) } & Até 25 anos & 30,66 & 10,14 & 2,769 & 0,064 \\
\hline & De 25 a 30 anos & 29,37 & 9,88 & & \\
\hline & Acima de 31 anos & 28,00 & 11,44 & & \\
\hline \multirow{3}{*}{ E- Preço da ação A nos últimos, seis meses do questionário } & Até 25 anos & 0,56 & 0,84 & 4,971 & $0,007^{* *}$ \\
\hline & De 25 a 30 anos & 0,78 & 0,91 & & \\
\hline & Acima de 31 anos & 0,85 & 1,00 & & \\
\hline \multirow{3}{*}{ F- Preço da ação B nos últimos seis meses do questionário } & Até 25 anos & $-0,31$ & 0,89 & 1,248 & 0,288 \\
\hline & De 25 a 30 anos & $-0,23$ & 0,94 & & \\
\hline & Acima de 31 anos & $-0,15$ & 1,00 & & \\
\hline \multirow{3}{*}{ G- Preço da ação $C$ nos últimos seis meses do questionário } & Até 25 anos & $-0,86$ & 2,65 & 0,330 & 0,719 \\
\hline & De 25 a 30 anos & $-1,00$ & 1,08 & & \\
\hline & Acima de 31 anos & $-1,03$ & 1,22 & & \\
\hline \multirow{3}{*}{ G1- Preço da ação D nos últimos seis meses do questionário } & Até 25 anos & 0,29 & 0,96 & 0,608 & 0,545 \\
\hline & De 25 a 30 anos & 0,31 & 1,01 & & \\
\hline & Acima de 31 anos & 0,18 & 1,03 & & \\
\hline \multirow{3}{*}{ H- Preço da ação E nos últimos seis meses do questionário } & Até 25 anos & $-0,96$ & 0,96 & 1,111 & 0,330 \\
\hline & De 25 a 30 anos & $-0,74$ & 2,35 & & \\
\hline & Acima de 31 anos & $-1,00$ & 1,13 & & \\
\hline \multirow{3}{*}{ Soma dos escores do item I do questionário (otimismo) } & Até 25 anos & 10,17 & 2,29 & 1,018 & 0,476 \\
\hline & De 25 a 30 anos & 10,32 & 2,25 & & \\
\hline & Acima de 31 anos & 9,93 & 2,75 & & \\
\hline \multirow{3}{*}{ Soma dos escores do item L do questionário (perfil do risco) } & Até 25 anos & 8,45 & 2,18 & 2,562 & 0,106 \\
\hline & De 25 a 30 anos & 7,92 & 1,92 & & \\
\hline & Acima de 31 anos & 8,13 & 2,24 & & \\
\hline
\end{tabular}

Notas: (a) As probabilidades de significância ( $p$-valor) referem-se ao teste Anova para amostras independentes. (b) Os valores de p-valor em negrito indicam diferenças significativas. (c) Os resultados significativos foram identificados com asteriscos, de acordo com o nível de significância, a saber: p-valor $<0.01^{* *}$ (nível de confiança de 99\%) e p-valor < $0.05 *$ (nível de confiança de 95\%).

Tabela 20: Avaliação dos escores médios referentes aos fatores de variáveis relativas ao risco, as ilusões cognitivas dos discentes pesquisados por escolaridade.

\begin{tabular}{|c|c|c|c|c|c|}
\hline Questões sobre medidas Psicométricas & Escolaridade & Média & D.P & Estatística T & P-valor \\
\hline \multirow{2}{*}{ Soma dos escores do item B do questionário (ilusão de controle) } & Graduação & 18,57 & 3,37 & 0,646 & 0,519 \\
\hline & Pós ou Especialização & 18,28 & 4,90 & & \\
\hline \multirow{2}{*}{ Soma dos escores do item C do questionário (atitude de risco) } & Graduação & 7,53 & 1,98 & $-0,710$ & 0,478 \\
\hline & Pós ou Especialização & 7,71 & 2,34 & & \\
\hline \multirow{2}{*}{ Soma dos escores do item D do questionário (melhor que a média) } & Graduação & 29,73 & 10,22 & 0,507 & 0,613 \\
\hline & Pós ou Especialização & 29,08 & 11,99 & & \\
\hline \multirow{2}{*}{ E- Preço da ação A nos últimos seis meses do questionário } & Graduação & 0,70 & 0,89 & 0,739 & 0,460 \\
\hline & Pós ou Especialização & 0,61 & 1,00 & & \\
\hline \multirow{2}{*}{ F- Preço da ação B nos últimos seis meses } & Graduação & $-0,22$ & 0,92 & 1,580 & 0,115 \\
\hline & Pós ou Especialização & $-0,40$ & 0,99 & & \\
\hline \multirow{2}{*}{ G- Preço da ação $C$ nos últimos seis meses } & Graduação & $-0,97$ & 1,07 & $-0,798$ & 0,425 \\
\hline & Pós ou Especialização & $-0,77$ & 4,37 & & \\
\hline \multirow{2}{*}{ G1- Preço da ação D nos últimos seis meses } & Graduação & 0,25 & 1,00 & $-0,326$ & 0,744 \\
\hline & Pós ou Especialização & 0,29 & 0,92 & & \\
\hline \multirow{2}{*}{ H- Preço da ação E nos últimos seis meses } & Graduação & $-0,92$ & 1,43 & 0,653 & 0,514 \\
\hline & Pós ou Especialização & $-1,02$ & 1,09 & & \\
\hline \multirow{2}{*}{ Soma dos escores do item I do questionário (otimismo) } & Graduação & 10,03 & 2,41 & $-2,005$ & $0,046 *$ \\
\hline & Pós ou Especialização & 10,61 & 2,38 & & \\
\hline \multirow{2}{*}{ Soma dos escores do item L do questionário (perfil de risco) } & Graduação & 8,39 & 2,11 & 2,712 & $0,007 * *$ \\
\hline & Pós ou Especialização & 7,69 & 2,31 & & \\
\hline
\end{tabular}

Notas: (a) As probabilidades de significância ( $p$-valor) referem-se ao teste t-Student para amostras independentes. (b) Os valores de p-valor em negrito indicam diferenças significativas. (c) Os resultados significativos foram identificados com asteriscos, de acordo com o nível de significância, a saber: p-valor $<0.01 * *$ (nível de confiança de $99 \%$ ) e p-valor $<0.05 *$ (nível de confiança de $95 \%$ ).

Percebeu-se que na associação entre os cursos definidos e os vieses de risco, quanto às ilusões cognitivas dos discentes pesquisados, expostas na Tabela 21, os alunos de pós-graduação apresentaram 
maior discordância nos fatores otimismo e perfil de risco em comparação com o grupo de alunos de graduação em Administração e Contábeis. As Tabelas 21 e 22 apontam que os alunos da pós-graduação não corroboram dos conceitos presentes no construto otimismo nem no perfil de risco.

Tabela 21: Avaliação dos escores médios referentes as questões de atitudes relativas ao risco e as ilusões cognitivas dos discentes pesquisados por gênero.

\begin{tabular}{|c|c|c|c|c|c|}
\hline Questões sobre medidas psicométricas & Gênero & Média & D.P & Estatística T & P-valor \\
\hline \multirow{2}{*}{ B8 Para ganhar no mercado de ações você tem de pensar positivamente. } & Masculino & 2,89 & 1,16 & $-2,529$ & $0,012^{*}$ \\
\hline & Feminino & 3,27 & 1,65 & & \\
\hline \multirow{2}{*}{ G O gráfico abaixo retrata o preço da ação $D$ nos últimos seis meses. } & Masculino & 0,11 & 1,01 & $-2,231$ & $0,026^{*}$ \\
\hline & Feminino & 0,33 & 0,97 & & \\
\hline \multirow{2}{*}{$\begin{array}{l}\text { L5 Eu arriscaria uma perda no retorno de curto prazo por uma possibilidade de uma taxa de } \\
\text { retorno mais alto no futuro. }\end{array}$} & Masculino & 3,08 & 1,08 & 2,748 & $0,006 * *$ \\
\hline & Feminino & 2,80 & 0,99 & & \\
\hline
\end{tabular}

Notas: (a) As probabilidades de significância ( $p$-valor) referem-se ao teste t-Student para amostras independentes. (b) Os valores de $p$-valor em negrito indicam diferenças significativas. (c) Os resultados significativos foram identificados com asteriscos, de acordo com o nível de significância, a saber: p-valor $<0.01^{* *}$ (nível de confiança de $99 \%$ ) e p-valor $<0.05 *$ (nível de confiança de 95\%). (d) A questão B8 foi invertida.

A Tabela 21 apresenta uma síntese dos resultados mais significativos para a variável gênero. As respostas relevantes que refletem as diferenças entre o gênero e que confirmam os objetivos desta pesquisa no contexto das decisões de investimento estão pontuadas a seguir: (a) As mulheres concordam mais que os homens na questão B8, relacionada a ilusão de controle; (b) Os alunos homens apresentaram uma percepção esperada do risco na ação $D$ de forma mais clara que as mulheres; (c) Os homens arriscariam uma perda no retorno de curto prazo por uma possibilidade de uma taxa de retorno mais alto no futuro, ao contrário das mulheres.

\section{CONSIDERAÇÕES FINAIS}

O desenvolvimento de novos estudos com base em amostras e contextos diversos contribui para a validação dos resultados empíricos que demonstram o desvio do comportamento do investidor, como predito pela Moderna Teoria de Finanças. Apoiados na premissa de racionalidade limitada de Simon (1955), os pressupostos das finanças comportamentais permitem analisar o comportamento real dos investidores no processo de tomada de decisão em ativos financeiros. Notavelmente, a análise do processo de decisões de investimento mostra-se complexa, uma vez que cada indivíduo apresenta atributos de personalidade diferentes e assume características psicológicas que assumem papéis fundamentais nos julgamentos de escolhas individuais (BAYSTOM; DROMS, 2000).

Ao assumir a perspectiva das finanças comportamentais, este estudo investigou as diferenças entre gêneros no contexto das decisões de investimento no mercado financeiro. A análise estatística evidenciou resultados significantes relativos às diferenças entre gêneros e outras variáveis sociodemográficas no tocante aos vieses cognitivos (ilusão de controle, otimismo e efeito melhor do que a média) e às dimensões de risco contempladas (atitude, percepção e perfil de risco).

A análise que comparou a presença do viés ilusão de controle evidenciou que os respondentes, em sua maioria, acreditam que para ganhar no mercado é preciso pensar positivamente e fazer análises adequadas para valores futuros. Quando ocorre a presença deste viés, o investidor acredita possuir um número elevado de informações. 
O viés do otimismo apresentou maior discordância entre os respondentes na alternativa de que se algo puder dar errado acontecerá. Este viés aponta que as escolhas feitas pelos entrevistados estão de acordo com suas crenças (MOSCA, 2009).

Para o efeito melhor do que a média, resultado do julgamento individual enviesado das próprias habilidades com relação às de seus pares, os resultados indicaram um índice médio de $60 \%$, demonstrando uma auto-avaliação superior das próprias capacidades. Corroborando com Lima (2003), os investidores, em sua maioria, atribuem uma capacidade elevada referente a suas habilidades para obter sucesso no mercado de capitais.

A análise da atitude de risco demonstrou uma tendência dos respondentes em optarem por opções de investimentos mais seguras. A opção de aplicação em investimentos da caderneta de poupança foi a que mais apresentou concordância dos discentes. A atitude risco busca medir o grau de incerteza dos investimentos realizados (PUGA, 2009).

A variável percepção de risco, apesar de as evidências empíricas, como de Castro et al. (2002), apontarem que seus entrevistados percebem o risco das opções de investimento de forma diferente, nesta investigação apresentou concordância na percepção de risco da ação D, sendo esta a que revelou a melhor percepção pelos respondentes.

A variável que compõe a escala do perfil de risco foi atribuída à concordância dos respondentes em tolerar ou arriscar uma perda imediata se houver um ganho maior no futuro. Puga (2009) relata que a incerteza quanto à obtenção de retorno esperado envolve alto grau de risco da alternativa escolhida por estes indivíduos.

Em resposta ao problema de pesquisa, os resultados apontaram que, no âmbito das especificidades de gênero houve presença significativa da ilusão cognitiva, ilusão de controle. No que se refere às dimensões de risco, a influência manifestou-se nas variáveis atitude e percepção de risco.

Quando o fator "gênero" foi associado ao viés ilusão de controle, os resultados revelaram que as mulheres acreditam que o ganho no mercado de ações está relacionado ao fator sorte. Assim, a percepção do gênero feminino está menos tendenciosa a este viés. Cavalheiro (2014) cita que quando estas respondentes estão menos confiantes em suas capacidades possuem inclinação menor para o comportamento enviesado pela ilusão de controle.

A influência do gênero na percepção de risco foi significativa, pois a percepção do preço da ação D apresentou resultado distinto. Constatou-se que o gênero masculino manifestou uma percepção mais clara da ação D que o gênero feminino.

Com relação ao fator "atitude de risco", os homens arriscariam mais diante da possibilidade de uma perda imediata e de retorno mais alto no futuro. O gênero feminino tende a optar pela alternativa que apresente mais segurança no mercado de capitais, concordando quanto à escolha de investimentos como a caderneta de poupança. Tal comportamento indica traços de aversão à perda, seguindo a diretriz de maior propensão para ganhos considerados certos. 
Os resultados apresentados revelam que a conduta do gênero masculino possui características mais arriscadas que as do gênero feminino. Melo (2008) considera que os homens são mais propensos a riscos do que as mulheres, eles tendem a correr riscos maiores se houver chances de retornos mais elevados. Para Carneiro (2014), a influência da atitude de risco, impulsiona os indivíduos a se sentirem mais confiantes em suas escolhas, aspecto presente também na ilusão de controle.

A contribuição importante que esta investigação proporciona é para o avanço da literatura financeira e para os estudos do comportamento. O reconhecimento dos aspectos psicológicos e cognitivos e das diferenças presentes no comportamento dos diferentes gêneros, diante dos resultados observados nas pesquisas empíricas, pode promover previsões consistentes que auxiliem as decisões organizacionais e individuais.

Uma das limitações da realização da pesquisa prende-se à falta de acesso aos investidores reais. As corretoras de investimentos não possuem autorização para ceder os dados pessoais e os contatos destes agentes. Este foi o fato que direcionou a escolha da amostra para os discentes que participaram deste estudo.

Esta pesquisa não teve a pretensão de concluir o assunto. A investigação se propôs a contribuir para os avanços dos estudos referentes ao comportamento do investidor no mercado de capitais, com a finalidade de apontar as diferenças presentes entre os gêneros masculino e feminino, com o intuito de aflorar novas interpretações e manifestações acadêmicas.

\section{REFERÊNCIAS}

ACKERT, L. F.; DEAVES, R.. Behavioral finance: psychology, decision-making, and markets. South-Western Cengage Learning, 2010

ANACHE, M.; LAURENCEL, L. C.. Finanças Comportamentais: uma avaliação crítica da moderna teoria de finanças. Revista CADE, Rio de Janeiro, v.12, n.1, p.83-120, 2013.

ANSOFF, H. I.. Estratégia empresarial. São Paulo: McgrawHill, 1965.

$B A B B I E, E$.. Métodos de pesquisa de survey. Belo Horizonte: UFMG, 2005.

BANDINELLI, M. B.. Finanças comportamentais: orientação ao perfil do investidor pessoa física. Monografia (Bacharelado em Administração) - Universidade Federal do Rio Grande do Sul, Porto Alegre, 2010.

BARBEDO, C. H. S.; SILVA, E. C.. Finanças Comportamentais: pessoas inteligentes também perdem dinheiro na Bolsa de Valores. São Paulo: Atlas, 2008.

BORSATO, J. M. L. S.. Análise do lucro passível de distribuição: um estudo descritivo. Revista Brasileira de Contabilidade, n.178-180, p.67-80, 2009.

CARNEIRO, A. K. N.. Narcisismo, Vieses Cognitos e Risco em Decisões de Investimento. Dissertação (Mestrado em Administração) - Faculdade Novos Horizontes, Belo Horizonte, 2014.
CASTRO JÚNIOR, F. H. F.; FAMÁ, R.. As novas finanças e a teoria comportamental no contexto da tomada decisão sobre investimentos. Caderno de Pesquisas em Administração, São Paulo, v.9, n.2, 2002.

CAVALHEIRO, E. A.. Tolerância ao risco: uma análise sob a ótica comportamental. Dissertação. (Mestrado em Administração) -Universidade Federal de Santa Maria, Rio Grande do Sul, 2010.

CHURCHILL JR., G. A.. A Paradigm for Developing Better Measures of Marketing Constructs. Journal of Marketing Research, v.16, n.1, p.64-73, 1979.

COLLIS, J.; HUSSEY, R.. Pesquisa em Administração: um guia prático para alunos de graduação e pós-graduação. 2 ed. Porto Alegre: Bookman, 2005.

DAMODARAN, A.. Avaliação de investimentos: ferramentas e técnicas para a determinação do valor de qualquer ativo. Rio de Janeiro: Qualitymark, 1997.

DINIZ, F. B.. Finanças comportamentais: um estudo sobre o perfil do investidor, o senso de auto controle e o grau de confiança nas decisões de investimentos no mercado de ações. Dissertação (Mestrado em Administração) Universidade Federal do Espírito Santo, Vitória. 2013.

FAMÁ, E. F.. Efficient Capital Markets: a review of theory and empirical work. The Journal of Finance, Chicago, v.25, n.2, p.383-417, 1970 . 
GAVA, A. M.; VIEIRA, K. M.. Tomada de decisão em ambiente de risco: uma avaliação sob a ótica comportamental. Revista Eletrônica de Administração, Porto Alegre, v.12, n.1, 2006.

GIL, A. C.. Como elaborar projetos de pesquisa. 5 ed. São Paulo: Atlas, 2010.

HAIR JÚNIOR, J. F.. Métodos de pesquisa em Administração. Porto Alegre: Bookman, 2006.

HEATON, J. B.. Managerial Optimism and Corporate Finance. Financial Management, v.31, n.2, p.33-45, 2002.

KAHNEMAN, D.; TVERSKY, A.. Prospect theory: an analysis of decision under risk. Econometrica, v.47, n.2, p.263-291, 1979.

KAHNEMAN, D.; TVERSKY, A.. The psychology of preferences scientific American, v.146, p.160-173, 1982

KIMURA, H.. Aspectos Comportamentais Associados às Reações do Mercado de Capitais. Revista de Administração de Empresas, São Paulo, v.2, n.1, p.1-14, 2003.

LIMA, M. V.. Um estudo sobre finanças comportamentais. RAE Eletrônica, São Paulo, v.2, n.1, p.1-19, 2003.

MACEDO JR., J. S.. Teoria do prospecto: uma investigação utilizando simulações de investimento. Tese (Doutorado em Engenharia de Produção) - Universidade Federal de Santa Catarina, Florianópolis, 2003.

MARKOWITZ, H.. Portfolio Selection. The Journal of Finance, New York, v.7, n.1, p.77-91, 1955.

MALHOTRA, N. K.. Pesquisa de Marketing: uma orientação aplicada. 3 ed. Porto Alegre: Bookman, 2004.

MELO, C. L. L.. Finanças Comportamentais: um estudo da influência da faixa etária, gênero e ocupação na aversão a perda. 2008. 130 f. Dissertação (Mestrado em Ciências Contábeis) - Universidade Federal do Rio Grande do Norte, Natal, 2008.

MOURA, A. G.. A história do risco: gênese do pensamento estatístico e o ensino de estatística na Universidade. Dissertação (Mestrado em Educação) - Universidade Católica de Goiás, Goiânia, 2005.

NEUMANN, J.; MORGENSTERN, O.. Theory of games and economic behavior. Princeton University Press, 1944.
PUGA, R.. Formação de investidores: supere a poupança e invista em ações no home broker. São Paulo: Elsevier, 2009.

SANVICENTE, A. Z.; MELLAGI FILHO, A.. Mercado de capitais e estratégias de investimento. São Paulo: Atlas, 1988.

SCHEIER, M. F.; CARVER, C. S.; BRIDGES, M. W. Distinguishing optimism from neuroticism (and trait anxiety, self-mastery, and self-esteem): A reevaluation of the Life Orientation Test). Journal of Personality and Social Psychology, v.67, n.6, p.1063-1078, 1994.

SCHUBERT, R.. Financial decision-making: are women really more risk averse?. American Economic Review, v.89, p.381385, 1999.

SCALON, C. A. C.. Gênero, família e trabalho no Brasil. Rio de Janeiro: FGV, 2005.

SHEFRIN, H.; STATMAN, M.. The disposition to sell winners too early and ride losers too long: theory and evidence. Journal of Finance, v.40, n.3, p.777-790, 1985.

SIMON, H. A.. A behavioral model of rational choice. Quarterly Journal of Economics, v.69, p.99-118, 1955.

SPECTOR, P. E.. Summated rating scale construction: an introduction. Los Angeles: Sage, 1992.

STATMAN, M.. Behavioral finance: past battles and future engagements. Financial Analysts Journal, v.55, n.6, p.18-27, 1999.

STERNBERG, R. J. Psicologia cognitiva. Porto Alegre: Artes Médicas Sul, 2000.

STREY, M. N.; CABEDA, S. T. L.; PREHN, D. R.. Gênero e cultura: questões contemporâneas. Porto Alegre: EDIPUCRS, 2004.

THALER, R. H.. The end of behavioral finance. Financial Analysts Journal, v.55, n.6, p.12-17, 1999.

TVERSKY, A.; KAHNEMAN, D.. Judgment under uncertainty: heuristics and biases. Science, v.185, n.4157, p.1124-1131, 1974.

URDAN, A. T.. Avaliação empírica da escala Servqual em serviços hospitalares: uma crítica e réplica ao estudo de Vinícius Sittoni Brasil. In: ENCONTRO DA ASSOCIAÇÃO NACIONAL DE PÓS-GRADUAÇÃO E PESQUISA EM ADMINISTRAÇÃO, 19. Anais. Rio de Janeiro: ANPAD, 1995. 